\title{
Interaction between optical fibre sensors and matrix cracks in crossply GFRP laminates. Part 2: Crack detection
}

\author{
H. Wang ${ }^{1}$, S.L. Ogin ${ }^{1}$, A.M.Thorne ${ }^{1}$ and G.T. Reed ${ }^{2}$ \\ ${ }^{1}$ School of Engineering \\ ${ }^{2}$ School of Electronics and Physical Sciences \\ University of Surrey, Guildford, Surrey GU2 5XH, UK
}

\section{SUMMARY:}

Polarimetric optical fibre sensors have been embedded within the $0^{\circ}$ ply and close to the $0 / 90$ interface of transparent cross-ply GFRP coupons. The coupons have been subjected to an increasing quasi-static load so that transverse ply cracks initiate and propagate across the coupon. Crack accumulation has been monitored using the optical output signal from the polarimetric sensor, strain measurements from a long gauge-length extensometer, load recordings during the test and by video recording of crack development. These combined observations have enabled a direct correlation to be made between matrix crack growth past the sensor and a step-change in the sensor response. The use of band-pass FFT filtering has demonstrated that such cracks could be detected in real time.

KEYWORDS: A. Smart materials B. Matrix cracking

\section{INTRODUCTION}

Optical fibre sensors are the subject of intense interest for detecting various types of damage in composite materials. Some of the early work on damage detection concentrated on using the attenuation of the intensity of the optical output due to fibre failure or bending losses induced in an area of damage (see e.g. Udd [1]). Other approaches have included the use of optical time domain reflectometry, optical coherence domain reflectometry, fibre Bragg grating sensors, Michelson interferometric sensors and polarimetric sensors (e.g. Bocherens et al [2]; 
Takeda et al [3]; Okabe et al [4,5]; Kwon et al [6]; Tsuda et al [7]; Murukeshan et al [8], Ussorio et al [9] ). Of these techniques, only Fibre Bragg grating (FBG) optical sensors possess the potential to detect matrix cracking damage, as both Takeda and colleagues and Ussorio and colleagues have shown recently (e.g. Okabe et al [4,5]; Ussorio et al [9]).

A difficulty encountered with FBG sensors, as Okabe and colleagues have noted, is that it is necessary to locate the sensors at stress concentrations where cracking is expected to occur. The advantage which integrating sensors have over FBG sensors is that an extensive portion of the composite can be monitored. In the polarimetric sensor, the optical core of the $\mathrm{Hi}-\mathrm{Bi}$ fibre, which has been pre-stressed during manufacture to produce a state of high birefringence, transmits orthogonally polarised components of light with different velocities. Longitudinal or lateral strains affect the stress birefringence, and hence the optical path lengths, producing a change in the relative phase of the orthogonally polarised optical signals. The interference of these signals results in a dynamic change in the output signal that can be used for damage detection. The two orthogonal optical axes, which lie in the core of the polarimetric fibre, are differentially affected by strain, leading to a concise sensor structure without the need for an additional reference fibre as required by a standard interferometric sensor such as the Michelson or Mach-Zehnder interferometer. This compactness is bought at the cost of a reduced longitudinal sensitivity (the polarimetric sensor has a longitudinal sensitivity about 100 times smaller than the Michelson interferometer) although there is an enhanced transverse sensitivity which is particularly useful for damage detection. Polarimetric sensors can detect various physical fields, for example temperature (Rasmussen and Scholl [10]), strain (Asundi et al [11]) pressure (Passy et al [12]; Norbert et al [13]) and they have been used in diverse applications ranging from acting as the basis of a weight sensor (Liu and Chuang [14]) to delamination detection in composite materials (Murukeshan et al $[8,15]$ ).

Sirkis et al $[16,17]$ developed a phase-strain model for polarimetric strain sensors based on fictitious residual strains, for which the phase-strain equation can be written as:

$$
\Delta \phi=\frac{2 \pi}{\lambda}\left(K_{1} \varepsilon_{1}+K_{2} \varepsilon_{2}+K_{3} \varepsilon_{3}\right) \Delta L
$$


where $\Delta \varphi$ is the relative phase change between the two polarisation modes caused by threedimensional strains $\varepsilon_{1}, \varepsilon_{2}$ and $\varepsilon_{3}$ (the three normal strains), where $\lambda$ is the wavelength of light in vacuum, and $K_{1}, K_{2}$ and $K_{3}$ are dimensionless coefficients which determine the contribution of each component of the normal strains to $\Delta \varphi$. $\Delta L$ is the sensing length. The change of phase of the optical output is thus determined by the change of strain state around the sensors.

Murukeshan et al [8] studied the detection of delaminations in composite laminates by embedding a polarimetric sensor in CFRP or GFRP laminates within which delaminations had been deliberately introduced. Changes in the optical output of the polarimetric sensor were related to the change in lateral strain due to the delaminations, demonstrating the feasibility of on-line health monitoring of composites using such a sensor. The present study uses a polarimetric sensor to detect the growth of matrix cracks in a cross-ply composite laminate. The transparent nature of the composites used in this work enables the time at which the cracks interact with the sensor to be determined directly.

\section{EXPERIMENTAL PROCEDURE}

\subsection{The polarimetric sensor}

Polarimetric fibre optical sensors (FOS) were embedded in (0/90/0) cross-ply laminates and some sensors were also embedded in unidirectional composites (the fabrication details of coupons containing sensors are given in [18]). The ply thicknesses of the laminates were $2.0 \pm 0.2 \mathrm{~mm}$. Coupons were $20.0 \pm 0.5 \mathrm{~mm}$ wide and aluminium end tabs, $20 \pm 1 \mathrm{~mm}$ long, were bonded to the coupons using adhesive (3M Scotch Weld 490). Grip inserts were specially machined to enable the optical fibres to emerge from the coupon and so that the coupons would fit into standard Instron wedge grips.

A polarimetric sensor was chosen for three reasons. Firstly, an integrating sensor is useful for matrix crack detection because it is usually not possible to predict the position of the first 
matrix crack in a cross-ply laminate under load. Secondly, a polarimetric sensor is sensitive to changes in the lateral strain field, and thirdly it is a simple sensor to construct and is potentially an inexpensive solution for damage monitoring in large composite structures.

High-birefringent single-mode polarisation-maintaining Panda fibres (obtained from Fujikura Europe Ltd) were used to manufacture the sensors. In most cases, the outer protective nylon coating and inner silicone coating were removed from the fibre using a coating stripper and a lens tissue soaked with high purity alcohol was used to clean the stripped fibre. Localisation of the gauge length within the composite was achieved by rotating the axes of the fibre through $45^{\circ}$ in the sensing section relative to the orientation of the lead-in/lead-out sections of the optical fibre. Splicing was carried out using a Fujikura fusion splicer (model FSM-20PM) using spark fusion and the gauge length of the sensor (i.e. the length between the two $45^{\circ}$ splices) was in the range from $80 \mathrm{~mm}$ to $100 \mathrm{~mm}$. The fibre lengths which emerged from the coupon were spliced, using $0^{\circ}$ splices, to the rest of the optical system (see Figure 1). This procedure enabled repeat use of the optical fibres carrying the input and output light to the rest of the optical system and produced minimum disruption to the optics.

\subsection{Experimental arrangement}

Linearly polarised light from a He-Ne gas laser, $633 \mathrm{~nm}$ operational wavelength, was launched into one of the axes of the fibre and the lead-out fibre was connected to a photo amplifier by a standard connector (see Figure 1). Separation of the orthogonal modes of the optical signal was achieved by bending the lead-out part of the optical fibre; this causes the loss of one of the modes through the cladding, so that only one mode is detected (Varnham et al [19]). Figure 1 is a schematic of an edge view of a specimen, showing the dynamic extensometer (with a gauge length of $50 \mathrm{~mm}$ ) for measuring longitudinal strain, and the end tabs. A standard optical fibre connector (FCPC type) was attached to the end of the lead-out fibre to connect it to a photo amplifier. The output from the photo amplifier was recorded simultaneously with the load and strain signals by the controller of an Instron servo-hydraulic testing machine (8000) operating at a sampling frequency of $1667 \mathrm{~Hz}$. 
Figure 2 shows a schematic of the overall experimental arrangement. The Instron testing machine was operated in load control mode at a loading rate of $0.6 \mathrm{kN} \mathrm{s}^{-1}$. Matrix crack propagation across the transparent composite coupons was recorded using a video camera, enabling the position of the crack relative to the sensor to be determined directly. A timer with a resolution of $0.01 \mathrm{~s}$ was placed beside coupons so that the time when the cracks past the sensor could be recorded. It should be noted that the time shown by the timer and the time recorded by the datalogger were not synchronised exactly. However, by touching the extensometer gently after the test began, and thus introducing spikes into the strain signal, the time difference between the timer and the computer datalogger could be obtained.

\section{EXPERIMENTAL RESULTS}

In [18], the interaction between matrix cracks and passive optical fibres was described. The results presented here show that transverse ply cracks in cross-ply laminates can be detected under quasi-static loading.

3.1 Behaviour of the polarimetric sensor under quasi-static loading.

The polarimetric sensor, when fabricated using stripped fibre, produced irregular but reproducible fringes when the specimens were loaded and unloaded. Figure 3(a) shows data taken from a coupon under a strain that increases linearly with time from $0 \%$ to about $0.325 \%$ in 10 seconds, and then reduces to zero again. The optical output shows irregular fringes during loading, and a mirror image of these fringes during unloading. When the same results are plotted as optical output against strain (see Figure $3(b)$ ), and hence the effect of time is removed, the fringes are of the expected form though surprisingly irregular, and are reproducible for both loading and unloading.

The transverse strains for a sensor embedded in the $0^{0}$ ply of a cross-ply laminate subjected to a longitudinal strain of $\varepsilon_{1}$ are given by $\varepsilon_{2}=-v_{12}^{\prime} \varepsilon_{1}$ and $\varepsilon_{3}=-v_{13}^{\prime} \varepsilon_{1}$ where $v_{12}^{\prime}$ and $v_{12}^{\prime}$ are 
the effective Poisson's ratios for the sensor. From equation (1), the optical response of the sensor is:

$$
\Delta \varphi=\frac{2 \pi}{\lambda} L\left(K_{1}-v_{12}^{\prime} K_{2}-v_{13}^{\prime} K_{3}\right) \varepsilon_{1}=C \varepsilon
$$

where $C$ is a constant. Equation (2) shows that when a polarimetric sensor is embedded in a cross-ply laminate, there is a linear relationship between the longitudinal strain applied to the coupon and the optical output phase change. This means that when the strain varies with time, the fringes induced by the change of strain will vary with time as well, as shown in Figure 3(a).

The irregularity of the fringes is related to the transverse sensitivity of the bare sensor. This was shown by testing a cross-ply coupon with an embedded sensor that was not stripped of its protective coatings. The optical fringes (Figure 4) are now uniform in terms of spacing and amplitude. In this case, the relatively soft silicone inner coating and the outer nylon coating have smoothed the irregular strains around the sensor caused by the adjacent reinforcing glass fibres, and as a consequence the optical fringes become very regular. However, stripped sensors were used in the crack detection experiments because (a) the sensors with the protective coatings had a very large diameter (about $1.0 \mathrm{~mm}$ ), and (b) the sensitivity of the sensors to matrix cracking is impaired when the transverse sensitivity is reduced by the sensor coatings.

\subsection{Detection of matrix cracks in cross-ply laminates}

It is well known that when a GFRP cross-ply laminate with a relatively thick transverse ply is loaded that transverse cracks will occur in the $90^{\circ}$ ply at a tensile strain of approximately $0.3 \%$ - $0.4 \%$ (see e.g. Boniface and Ogin [20]). If the cross-ply laminate has a $90^{\circ}$ ply thickness of $1 \mathrm{~mm}$ as in this work, then crack development normally occurs from the coupon edges and at any location within the coupon gauge length. Hence, as indicated in the schematic diagram in Figure 1, cracks can develop (a) within both the extensometer and sensor gauge lengths, (b) 
outside the extensometer gauge length but within the sensor gauge length, or (c) outside both the extensometer and sensor gauge lengths. A study of the sensor response to crack development in these different positions demonstrates the ability of the sensor to detect matrix cracking damage.

\subsubsection{Cracks occurring within both the extensometer and sensor gauge lengths}

The behaviour of the load, strain and optical output signals when a crack develops within both the extensometer and sensor gauge lengths are shown in Figures 5 (a) and $5(b)$, and stills from the video recording of crack development are shown in Figures 5(c) and 5(d). The long black felt tip line on the surface of the coupon parallel to the coupon length in Figures 5(c) and 5(d) shows the approximate position of the embedded sensor; a similar black line on the surface across the coupon shows the approximate position of one of the $45^{\circ}$ splices of the sensor. In this example, the matrix crack grew across the full width of the coupon at a time on the datalogger of $33.68 \mathrm{~s}$ (this is shown on the timer as $34.08 \mathrm{~s}$ since synchronisation of the times produced a difference in this example of $0.4 \mathrm{~s}$ between the starting of the timer and the beginning of datalogging by the Instron controller). Figure $5(\mathrm{a})$ shows the load and strain plotted as a function of time for about half-a-second before and after crack development and Figure $5(b)$ shows the behaviour of the strain and the optical output over the same time period. Figures 5 (c) and 5(d) show two consecutive frames of the video-recording within which the crack both initiated and grew across the coupon (crack initiation and propagation across the full width of the coupon occurred in this example within less than $1 / 100$ th second, which is the resolution of the timer). The arrow in Figure 5(d) shows the position of the crack, which is partially obscured by the extensometer.

This experimental arrangement allows a link to be made between crack growth (recorded by the video recorder) and the optical, load and strain changes. When the transverse ply crack grows across the laminate, two effects produce an immediate increase in length of the coupon. Firstly, the compressive residual thermal strain within the $0^{0}$ plies (as a consequence of fabrication) is relaxed in the vicinity of the transverse ply crack producing a lengthening of the coupon. Secondly, in addition to this local relaxation of thermal strain, the compliance of 
the coupon increases as a result of crack formation, producing an additional increase in coupon length (Boniface et al [21]; Bassam et al [22]). The fluctuations in the load and strain signals can therefore be explained as follows. The sudden increase in coupon length is recorded by the datalogger as a strain increase of about $10 \mu \varepsilon$. The servohydraulic testing machine, which is operating under load control, detects a sudden drop in load as a result of the increase in coupon length, and the testing machine attempts to correct the load to the demand signal. The resulting fluctuation in load is rapidly damped but the load fluctuations lead to strain fluctuations over the same timescale, as can be seen in Figure 5(a).

Focusing now on the response of the polarimetric sensor, Figure 5(b) shows the strain signal together with the optical output over the same time period. In this plot, the optical output signal has been magnified substantially and the noise on the output is obvious. However, this noise does not obscure the step change in the optical output that coincides precisely with the change in the strain signal, and both changes coincide with the growth of the crack across the specimen as recorded by the video recorder (Figures 5(c) and 5(d)). Additional work (see below) has shown that the change in the optical signal is caused by the passage of the crack tip past the sensor.

3.2.2. Cracks occurring outside the extensometer gauge length but within the sensor gauge length

Figures 6(a) and 6(b) show the load, strain and optical signal changes when a crack develops outside the extensometer gauge length but between the two $45^{\circ}$ splices of the sensor. The crack in this example had grown partially across the coupon but had not yet reached the position of the sensor by $61.08 \mathrm{~s}$ on the timer which is $60.68 \mathrm{~s}$ on the datalogger (the time difference has been explained above). At a time of $61.58 \mathrm{~s}$ on the timer, the crack grew rapidly across the remaining width of the coupon, past the sensor, in a time of less than $1 / 100^{\text {th }}$ of a second. In this case, as shown in Figure 6(a), the extensometer does not detect the crack because the crack development is outside the extensometer gauge length and, as Figure 6(a) shows, there is no step-change in the strain signal. However, as before, the matrix crack leads to an increase in coupon length, so the load drops slightly before recovering. The 
resulting fluctuation in overall specimen length as a result of the load drop is detected by the extensometer.

Although the extensometer cannot detect the crack in this position, Figure 6(b) shows that the polarimetric sensor can detect the crack since the crack development is within the sensor gauge length. Consequently, a step-change of optical output is seen when the crack grows past the sensor position. As Figure 6(b) shows, this step-change in optical output occurs at the same time as the fluctuations in strain, which in turn correspond to the time when the crack grew past the sensor, as confirmed by Figures 6(d) and 6(e).

\subsubsection{Cracks occurring outside both the extensometer and sensor gauge lengths}

When a crack develops both outside the extensometer gauge length and outside the sensor gauge length, there is neither a step-change in strain recorded by the extensometer nor a step-change in the optical output recorded by the sensor. Figures 7 (a) to 7 (d) show such an example. In this case, the load and strain fluctuations in Figure 7(a) suggest that a crack has formed at $82.08 \mathrm{~s}$ on the timer (81.68 s on the datalogger time axis of Figures $7(a)$ and $7(b)$ ). The lack of a step-change in strain and optical output in Figure 7 (b) suggests that the crack has developed outside the extensometer gauge length. This is confirmed by Figures 7(c) and 7 (d) which show that the crack developed about $20 \mathrm{~mm}$ beyond the position of the second $45^{\circ}$ splice.

\subsection{Identification of the critical event for crack detection}

In the experiments described so far, it is difficult to establish whether the step-change in the optical output is a consequence of the detection by the sensor of the overall strain change of the coupon when a crack develops within the sensor gauge length, or whether the crack growing past the sensor is the important event. Additional experiments were required to clarify this point.

Circular holes, $8 \mathrm{~mm}$ in diameter, were drilled at the centre of cross-ply laminate coupons containing sensors, so that the sensor lay to one side of the hole and at about $3 \mathrm{~mm}$ from the hole edge. The hole acts as a strain concentrator, and when cracks initiate from the hole, they develop either on the sensor side of the hole, or on the side of the hole that does not contain the sensor. Hence, the significance of cracks passing the sensor itself can be 
established. The coupons were again loaded in the servo-hydraulic testing machine under load control, at a loading rate of $0.7 \mathrm{kN} \mathrm{s}^{-1}$.

Figure 8 shows a plot of strain and optical output against time, together with video images that show the development of the first three cracks. The strain signal increases in a roughly linear manner in Figure 8(a), except for step-changes in strain when cracks 1, 2 and 3 develop. However, the only step change in the strain signal which corresponds to a step change in the optical signal occurs for crack 2, which developed at about 15.9 seconds on the same side of the hole as the sensor (the position of the sensor is again indicated roughly by a felt tip black line on the coupon surface). Cracks 1 and 3, which developed on the side of the hole away from the sensor, did not affect the optical output of the sensor. Such results confirm that stepchanges in the optical signal are due to cracks growing within the $90^{\circ}$ ply past the sensor which is located in the $0^{0}$ ply, near the $0 / 90$ interface. Cracks which do not grow past the sensor do not produce a step-change in the optical signal.

\section{CRACK DETECTION USING THE POLARIMETRIC SENSOR AND AN FFT BAND PASS FILTER}

The experimental results in Figures 5 to 8 show that there is a step-change in the optical output of the polarimetric sensor when a transverse ply crack grows past the embedded sensor. However, as Figure 5 shows, for example, the step-change in the signal can sometimes be difficult to distinguish from the background noise. For practical applications, a real-time monitoring system requires that the step change in the optical signal due to matrix crack development can be clearly distinguished even if there is significant background noise. In this section, it is demonstrated that this can be achieved using an FFT band-pass filter.

Figure 9 shows output optical signals from a coupon subjected to an increasing load over a 40 second period at constant loading rate of $0.01 \mathrm{kNs}^{-1}$, during which 5 cracks developed (as determined from a video recording of the test). An FFT analysis of this period, in terms of signal amplitude against frequency is shown in Figure 10(a). For comparison, Figure 10(b) shows the FFT analysis of a period of 50 seconds when no cracks occurred in the sample in 
the same test. In Figure 10(a), the FFT analysis shows peaks at about $20 \mathrm{~Hz}, 50 \mathrm{~Hz}, 75 \mathrm{~Hz}$, $100 \mathrm{~Hz}, 150 \mathrm{~Hz}, 200 \mathrm{~Hz}, 320 \mathrm{~Hz}$ and a collection of peaks at about $65 \mathrm{~Hz}$. The spectrum also contains strong contributions from low frequencies $(<5 \mathrm{~Hz})$ due to the irregularity of the optical fringes. The optical spectrum shown in Figure 10(b) is almost identical to that shown in Figure 10(a), despite the development of the five cracks during the period of Figure 10(a), although there are some small changes in the amplitudes of the peaks. The Fourier transform spectrum of a step-change is, of course, composed of a series of frequencies extending from almost zero to infinity with decreasing amplitude (e.g. Kraniauskas [23]) but the signal to noise ratio is small for the 5 step changes which occur during crack development in Figure 9 and hence the cracks cannot be identified in the FFT analysis. To determine the time at which the step changes occur (i.e. when the cracks develop), band pass filtering needs to be used to observe the time domain signal with the noise frequencies removed.

Unlike the FFT analysis, which shows the contributions of different frequency components of the spectrum, the use of a FFT filter can provide information about the contributions of a band of frequencies to the spectrum over a particular period of time. When the significant frequency range has been identified, the filtering enables the signal to noise ratio to be greatly improved. The value of using a band-pass FFT filter to produce the results is shown in Figure 11, which is an analysis of the optical data of Figure 9 but only allows frequencies between $100-150 \mathrm{~Hz}$ to pass through and blocks other frequencies. It is clear that five peaks emerge: at 143.7 seconds, 145.8 seconds, 154.3 seconds, 165.7 seconds and 175.3 seconds. Careful inspection of the optical signals, which will be shown later, indicates that the cracks had propagated past the sensor at these particular times. The filtering process has enabled the contributions of the step-changes to the frequency spectrum to be distinguished from the original information.

The amplitudes shown in Figure 11 are the contributions of frequencies between $150-200 \mathrm{~Hz}$ to the amplitudes of the five peaks when the cracks form. To distinguish the contributions of different frequency components to the spectrum, different band-pass FFT filters were applied to the same set of optical data and the results are shown in Figure 12 for the band pass ranges $5-50 \mathrm{~Hz}, 50-100 \mathrm{~Hz}, 100-150 \mathrm{~Hz}, 150-200 \mathrm{~Hz}, 200-250 \mathrm{~Hz}$ and $250-300 \mathrm{~Hz}$. 
Contributions of different bands of frequencies to the amplitudes of each of the five peaks shown in Figure 12 are plotted in Figure 13. In this figure, the amplitude of each of the five peaks for the different frequency ranges is plotted against the mean value of the frequency range. The figure shows that the Fourier transform spectrum of the step-changes in the optical signal is composed of a series of frequencies. The contributions of different frequencies obviously varies when the band of frequencies analysed is moved to higher values. Note that in Figure 13, each data point presents the contribution to the amplitude of the peak by a band of frequencies $50 \mathrm{~Hz}$ wide ( $45 \mathrm{~Hz}$ for the first column of the data).

The frequency analysis above suggests that the lower frequency of the band pass filter should be about $100 \mathrm{~Hz}$ to block out irrelevant low frequencies, and the highest frequency taken should be about $300 \mathrm{~Hz}$ to obtain a good signal/noise ratio. Figure 14(a) shows the band-pass filtered results of the time domain optical signal based on these parameters. In Figures 14(b) to $14(\mathrm{f})$, the occurrence of the five cracks identified as $A$ to $E$, is compared with a more detailed analysis of the data in Figure 9. The occurrence of each crack, labelled $A$ to $E$, is accompanied by a step-change in the optical output. Figure 14 shows that real time monitoring of crack development would be possible by applying an FFT band-pass filter to the output from the polarimetric sensor enabling the onset of cracking to be distinguished from background noise.

\section{DISCUSSION}

The present work has shown that a polarimetric sensor can be used to detect the onset of matrix cracking in a laminate due to the step-change in the optical signal that occurs when the crack grows past the sensor, but the precise origin of the step-change, and its magnitude, are not easy to predict.

As mentioned in Section 3.2, when a transverse ply crack grows across a laminate as a result of an applied mechanical load, two effects produce an immediate increase in the length of the coupon. Firstly, the compressive thermal strain within the $0^{0}$ plies is relaxed around the crack producing a lengthening of the specimen. Secondly, in addition to the local relaxation of 
thermal strain, the compliance of the specimen increases as a result of crack formation. An additional effect is the change in the transverse strain related to the local change in the Poisson's ratio of the laminate as a consequence of the development of a crack (Smith and Wood [24]).

These strain changes can all be expected to change the sensor output for the following reasons. Firstly, when the polarimetric sensor is positioned close to the $0 / 90$ interface, as in these experiments, the sensor will experience a sudden large local change in strain state as a result of the crack passing the sensor. Indeed, experimental measurements using the Raman effect with a Kevlar fibre embedded in the $0^{0}$ ply near the 0/90 interface (Arjyal et al [25]) suggest that when a crack develops the local longitudinal strain magnification in the $0^{0}$ ply close to the $0 / 90$ interface is about 7 . Secondly, the global strain change in the coupon due to the compliance change arising from crack formation will produce a longitudinal strain change in the sensor. However, it has been shown here that only cracks that pass adjacent to the sensor are detected, from which it can be inferred that the strain due to the compliance change does not produce a step-change in optical output. Hence, it can be concluded that the step-change is induced by the complex interaction between the changes in local strains that accompany crack formation (both longitudinal and transverse local strains) and the embedded sensor.

The polarimetric sensor is an integrating sensor and the magnitude of the change in the optical output depends on the integrated effect of the local strain changes on the path difference for both the "fast" and "slow" optical axes of the sensor. These, in turn, depend on the orientation of the optical axes of the Hi-Bi fibre with respect to the axes of the composite. In these experiments, no attempt has been made to control the relative orientation of the optical axes of the fibre with respect to the composite axes. Sectioning of the composites (Wang, [26]) has shown that not only does the initial orientation of the sensor axes vary from coupon to coupon with respect to the composite principal axes, but that the sensors also have differing degrees of twist. Hence, it can be appreciated that the prediction of the magnitude of the step-change in the optical signal is complex. However, neither the initial orientation of the sensor axes, nor the degree of twist of the sensor detracted from the sensor's ability to detect 
cracks that occur anywhere within its gauge length.

\section{CONCLUSIONS}

A low-cost, optical fibre system based on a polarimetric sensor can be used to detect matrix crack development under quasi-static loading in cross-ply GFRP laminates. There is a stepchange in the optical output when cracks grow in the transverse ply adjacent to the sensor. This step-change can be revealed using standard FFT band-pass filtering, if necessary. The polarimetric sensor can detect cracks that occur anywhere within the sensor gauge length and could provide the basis of a low-cost monitoring system for damage detection in large composite structures within aerospace or civil infrastructure applications.

\section{ACKNOWLEDGEMENTS}

The authors would like to thank Mr Reg Whattingham for technical assistance during this work.

\section{REFERENCES}

1. Udd E. Fibre optic smart structures. New York, John Wiley \& Sons, 1995

2. Bocherens E, Bouraseau S, Dewynter-Marty V, Py S, Dupont M, Ferdinand P Berenger H. Damage detection in a radome sandwich material with embedded fibre optic sensors. Smart Materials and Structures 2000;9:310-315.

3. Takeda N, Kosaka T, Hotate K, Saida T. Preliminary studies on identification of mechanical loading by distributed fibre optic sensors. US-Japan workshop on smart materials 1997: 227-234.

4. Okabe Yoji, Tsuji Ryohei, Takeda Nobuo. Application of chirped fiber Bragg grating sensors for identification of crack locations in composites. Composites Part A: Applied Science and Manufacturing, 2004; 35: 59-65 
5. Okabe Yoji, Mizutani Tadahito, Yashiro Shigeki and Takeda Nobuo. Detection of microscopic damages in composite laminates: with embedded small-diameter fiber Bragg grating sensors. Composites Science and Technology, 2002; 7-8: 951-958

6. Kwon I, Kim G, Hong C. Simultaneous sensing of the strain and points of failure in composite beams with an embedded fibre optic Michelson sensor. Composites Science and Technology 1997; 57: 1639-1651.

7. Tsuda $\mathrm{H}$, Takahashi J, Urabe K. Damage monitoring of carbon fibre-reinforced plastics with Michelson interferometric fibre-optic sensor. Journal of Materials Science 1999; 34: 4163-4172.

8. Murukeshan $\mathrm{V}$, Chan $\mathrm{P}$, Seng $\mathrm{O}$, Asundi A. On-line health monitoring of smart composite structures using fibre polarimetric sensor. Smart Materials and Structures 1999;8:544-548.

9. Ussorio M, Wang H, Ogin S L, Thorne A M, Reed G T. Use of Fibre Bragg Gratiings for damage detection in cross-ply laminates. In proceedings of the conference "Advancing with Composites - 2003", Milan (Italy), May 2003.

10. Rasmussen J C, Scholl B. Fibre optic polarimetric temperature sensor with high sensitivity. In: Proceedings SPIE, The International Society for Optical Engineering. 1997; 3121: $249-258$.

11. Asundi A, Cheng H K, Toh S L. Effect of input polarization angle on force sensitivity of embedded single mode polarimetric sensors. In: Proceedings SPIE International Society of Optical Engineering. 1996; 2872: 79-86.

12. Passy R, Gama A L, Gisin N. Pressure dependence of polarization mode dispersion in Hi-Bi fibres. Journal of Lightwave Technology. 1992; 10(11): 1527-1531.

13. Norbert F, Markus S, Wojetk J. Dynamic pressure sensing with a fibre optic polarimetric pressure transducer with two-wavelength passive quadrature readout. Applied Optics 1998; 37(4): 663-671.

14. Liu G, Chang S L. Polarimetric optical fibre weight sensor. Sensors and Actuators 1998; 69: 143-147

15. Murukeshan V M, Chan $P Y$, Ong L S, Asundi A. Effects of different parameters on the performance of a fiber polarimetric sensor for smart structure applications. Sensors and Actuators 2000; 80: 249-255 
16. Sirkis J, Lo Y L. Phase-strain model for polarimetric strain sensors based on fictitious residual strains. Journal of Intelligent Material Systems and Structures. 1994; 5: 494-500. 17. Sirkis J. An unified approach to phase-strain-temperature models for smart structure interferometric optical fibre sensors. Optical Engineering, 1991; 32(4): 752-773.

18. Barton E, Ogin S L, Thorne A M, Reed G T, Interaction between optical fibre sensors and matrix cracks in crossply GFRP laminates. Part 1: passive optical fibres. Composites Science and Technolog,. 2000; 61: 1863-1869.

19. Varnham M, Barlow A, Payne D, Tarbox E. Coiled-birefringent-fibre polarisers. Optics letters, 1984;9:306-308.

20. Boniface L, Ogin S L. Application of the Paris equation to the fatigue growth of transverse ply cracks. Journal of Composite Materials 1989; 23: 735-754

21. Boniface L, Ogin S L, Smith $P$ A. Strain energy release rates and the fatigue growth of matrix cracks in model arrays in composite laminates. In: Proceedings of Royal Society, London A, 1991: 427-444.

22. Bassam $\mathrm{F}$, Boniface $\mathrm{L}$, Jones $\mathrm{K}$, Ogin $\mathrm{S} \mathrm{L}$. On the behaviour of the residual strain produced by matrix cracking in crossply laminates. Composites Part A 1998;29A:14251432.

23. Kraniauskas P. Transforms in signals and systems. Addison-Wesley Publishing Company, 1991

24. Smith P A, Wood J R. Poisson's ratio as a damage parameter in the static tensile loading of simple crossply laminates. Composites Science and Technology, 1990; 38(1): 85-93

25. Arjyal B, Galiotis C, Ogin S L, Whattingham R. Residual strain and Young's modulus determination in crossply composites using an embedded aramid fibre strain sensor. Composites Part A 1998;29A:1363-1369.

26. H. Wang. The use of a polarimetric sensor to detect matrix cracking damage in composite laminates. Ph. D. Thesis, University of Surrey, 2003. 


\section{Figure captions}

Figure 1. Schematic of the optical arrangement showing a $(0 / 90)_{s}$ coupon with transverse cracks in the $90^{\circ}$ ply, viewed from the edge.

Figure 2 Schematic of the overall experimental arrangement.

Figure 3. Optical response of a polarimetric sensor embedded in a cross-ply laminate under quasi-static loading.
(a). The strain and optical signal when plotted against time for loading and unloading.
(b). Optical fringes with the optical signal plotted against strain, for both loading and unloading.

Figure 4 Optical fringes from an embedded polarimetric sensor with inner coating and outer coating intact.

Figure 5 Propagation of a crack within both the extensometer gauge and sensor gauge lengths.
(a) Change of load and strain signals with time.
(b) Change of strain and optical signals with time.
(c)-(d) Video images of the time when the crack passed the sensor. (The difference between time on the $x$-axis and time shown on the timer is $0.4 \mathrm{~s}$; the arrow indicates the position of the crack.)

Figure 6 Propagation of a crack outside the extensometer gauge but within the sensor gauge lengths.
(a) Change of load and strain signals with time.
(b) Change of strain and optical signals with time.
(c)-(e) Video images of crack development. (The difference between time on the x-axis and time shown on the timer is $0.4 \mathrm{~s}$; the arrow indicates the position of the crack.)

Figure 7 Propagation of a crack outside both the extensometer and sensor gauge lengths.

(a) Change of load and strain signals with time.

(b) Change of strain and optical signals with time.

(c)-(d) Video images of the time when the crack passed the sensor. (The difference between time on the $\mathrm{x}$-axis and time shown on the timer is $0.4 \mathrm{~s}$; the arrow indicates the position of the crack.)

Figure 8. Detection of cracks around a circular hole in a cross-ply laminate.

(a) Strain and optical output signals of cracks 1,2 and 3;

(b) Video images of crack development: only crack 2, which passes the sensor, produces a change in the optical output.

Figure 9. Optical output from a sensor embedded in a crossply coupon over a 40 second period when 5 cracks passed the sensor.

Figure 10. FFT analysis of the optical output signals shown in Figure 9.

(a). FFT analysis of the optical output signals shown in Figure 9.

(b). FFT analysis of the optical output signals over 50 seconds when no cracks occurred.

Figure 11. Band pass (100-150 Hz) FFT filtered optical signal of the data of the data shown in Figure 9

Figure 12 Band pass FFT filtered optical signal of the data shown in Figure 9. Band pass ranges are:
(a). $5-10 \mathrm{~Hz}$; (b). $50-100 \mathrm{~Hz}$; (c). $100-150 \mathrm{~Hz}$;
(d). $150-200 \mathrm{~Hz}$; (e). $200-250 \mathrm{~Hz}$; (f). $250-300 \mathrm{~Hz}$; 
Figure 13 Contributions of different frequency ranges to the five peaks shown in Figure 12.

Figure 14 Transverse crack detection by an embedded polarimetric sensor
(a) Band pass filtered optical signal using a band pass range of $100-300 \mathrm{~Hz}$;
(b) The optical output associated with of Crack A;
(c) The optical output associated with of Crack B;
(d) The optical output associated with of Crack C;
(e) The optical output associated with of Crack D;
(f) The optical output associated with of Crack E. 
Figure 1

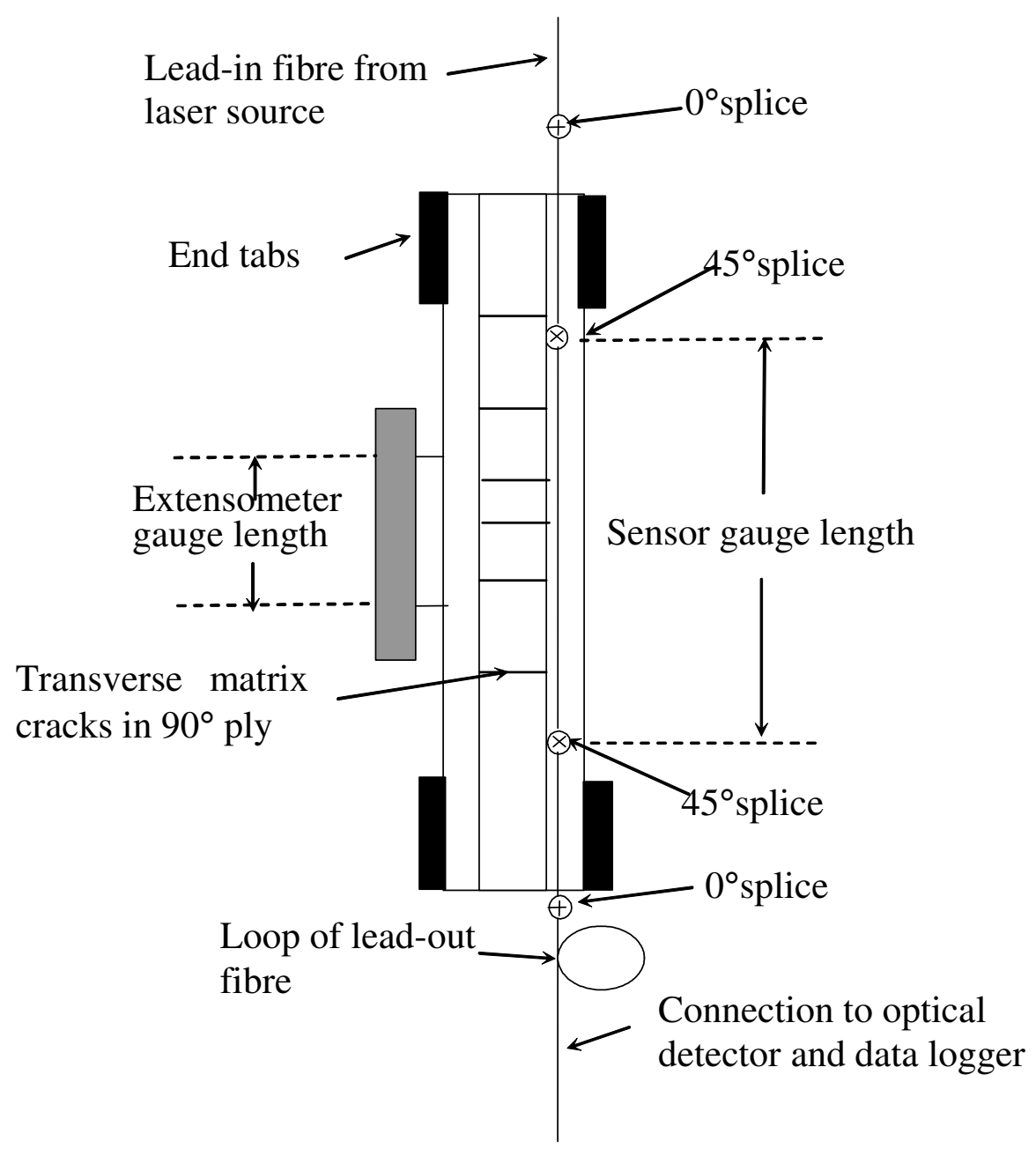


Figure 2

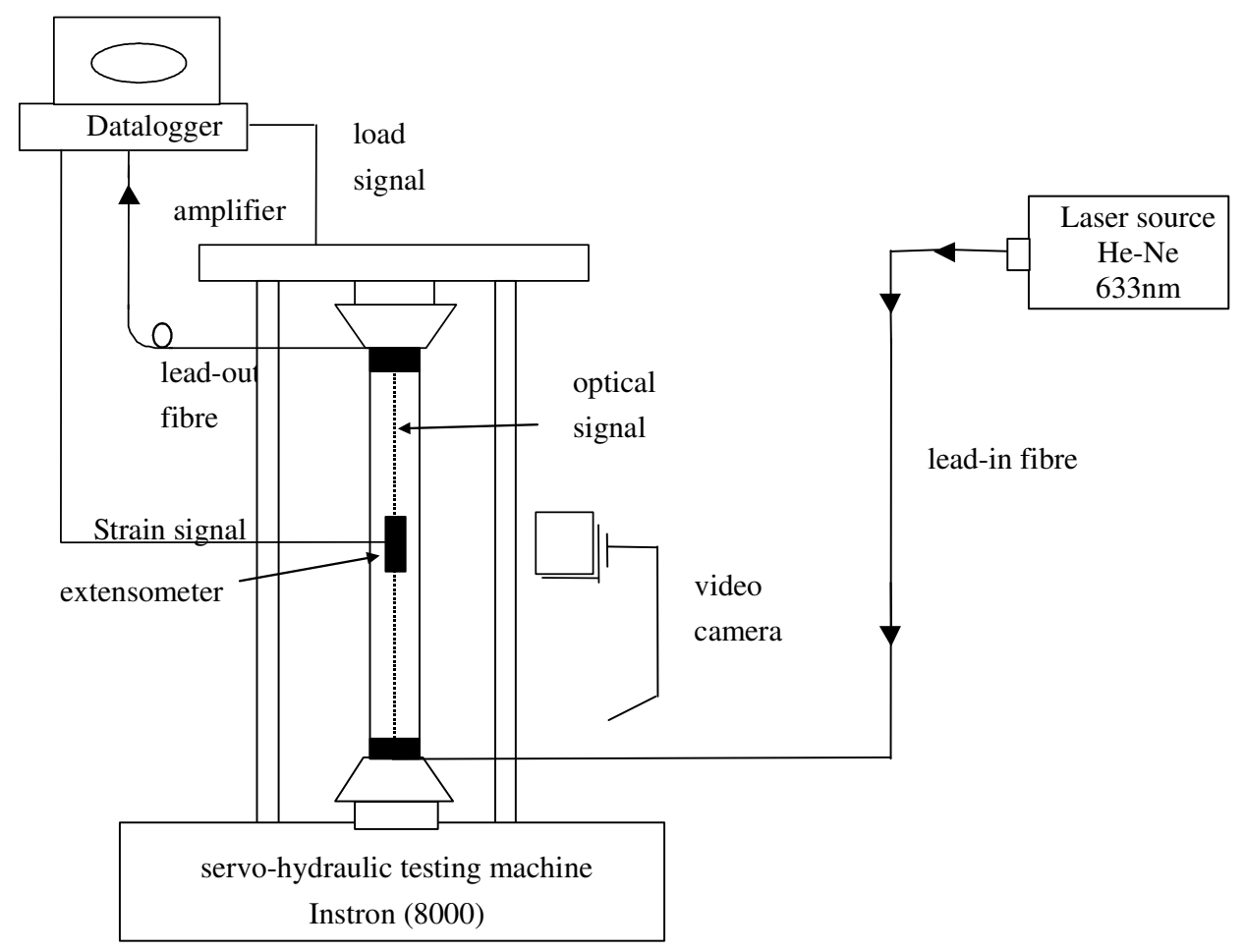


Figure 3

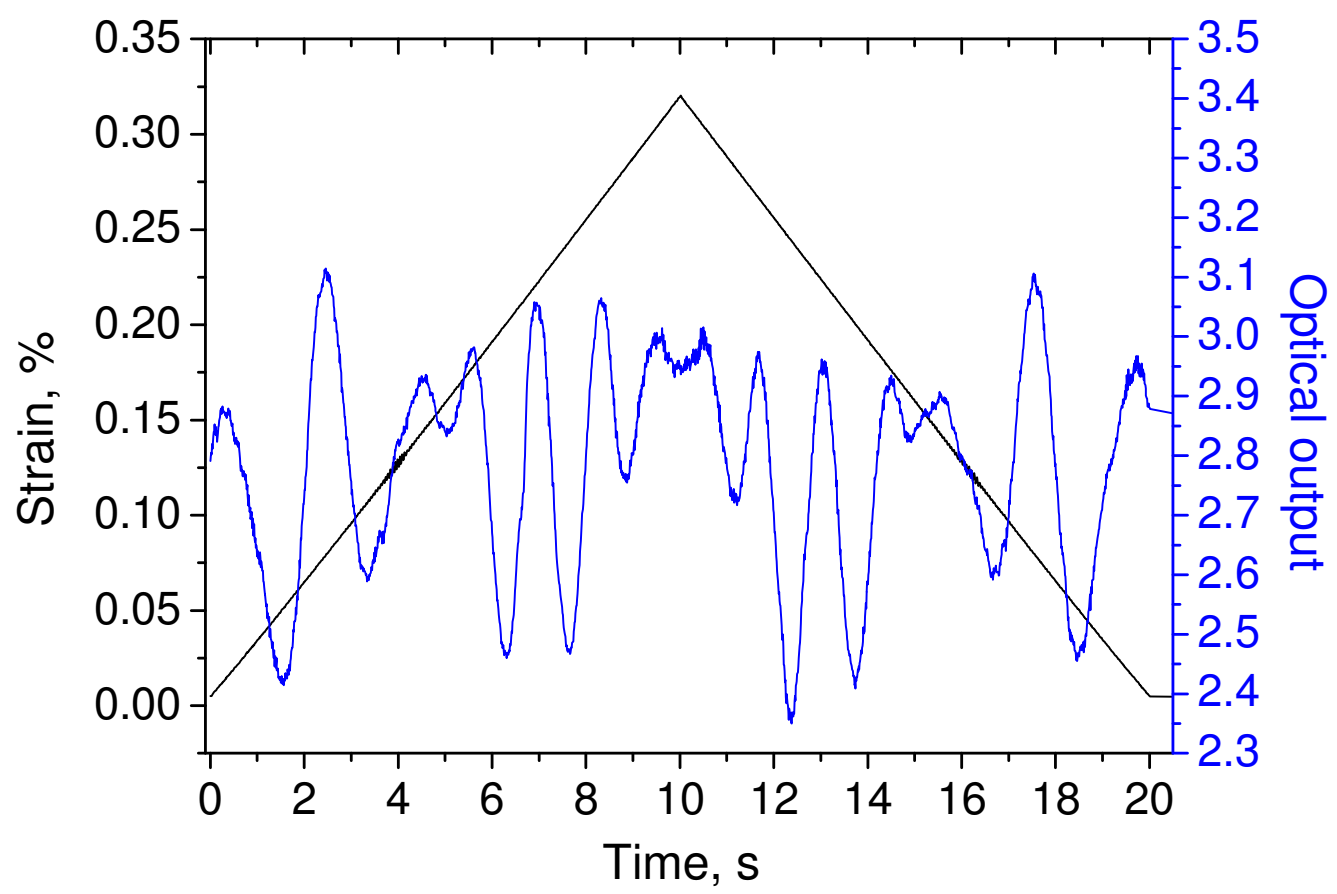

(a)

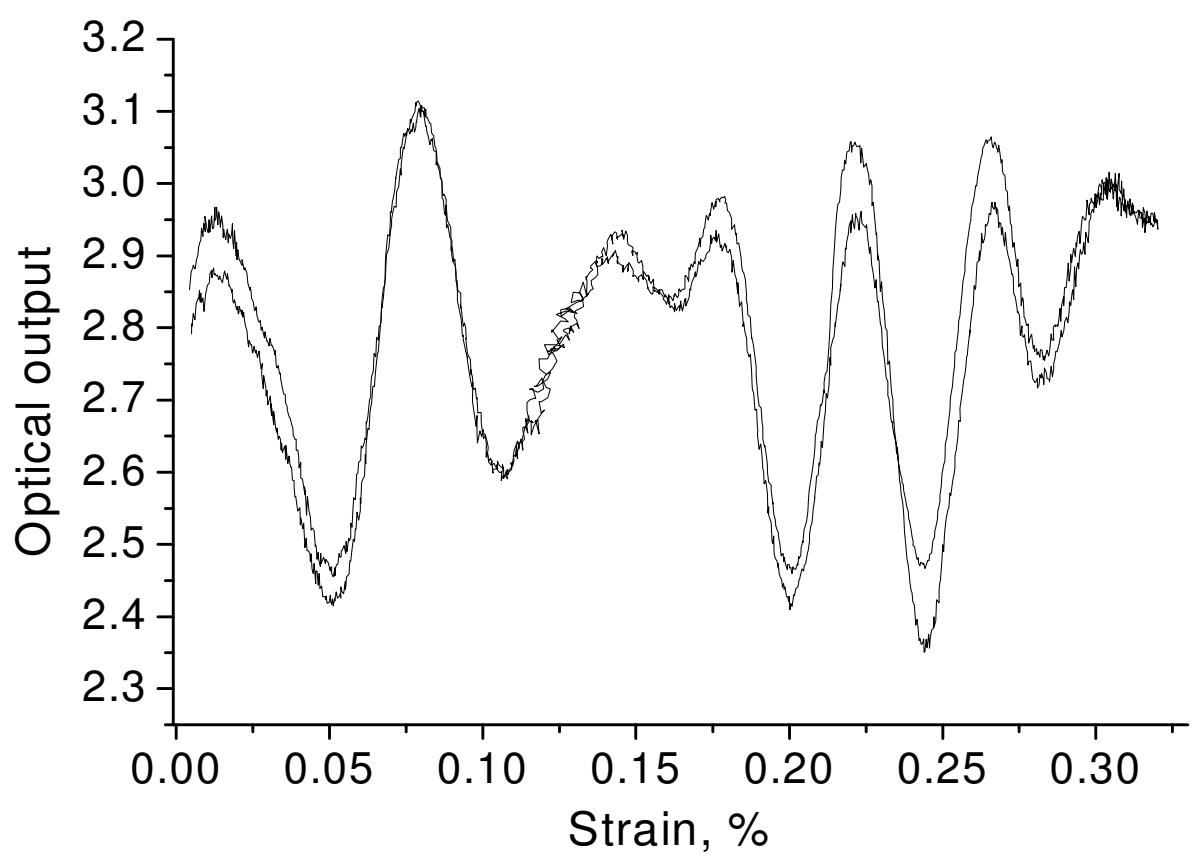

(b) 
Figure 4

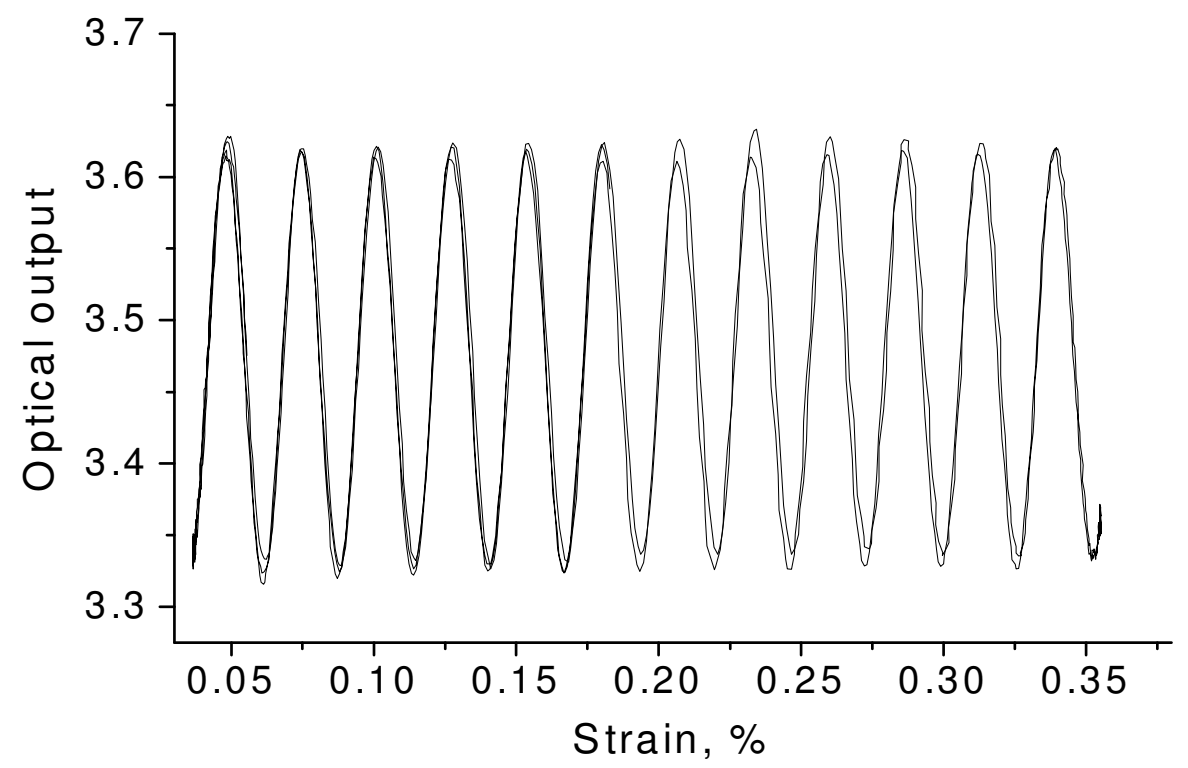


Figure 5

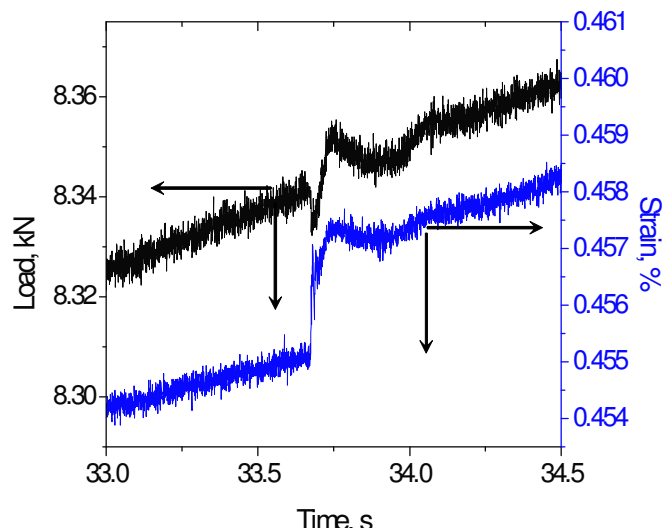

(a)

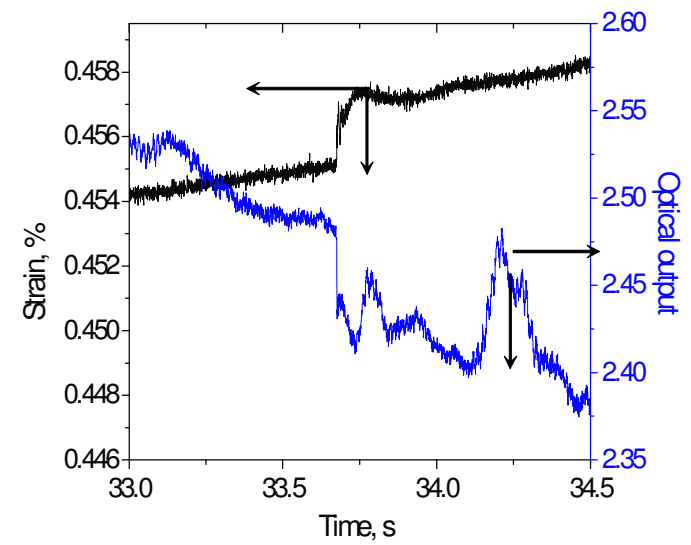

(b)

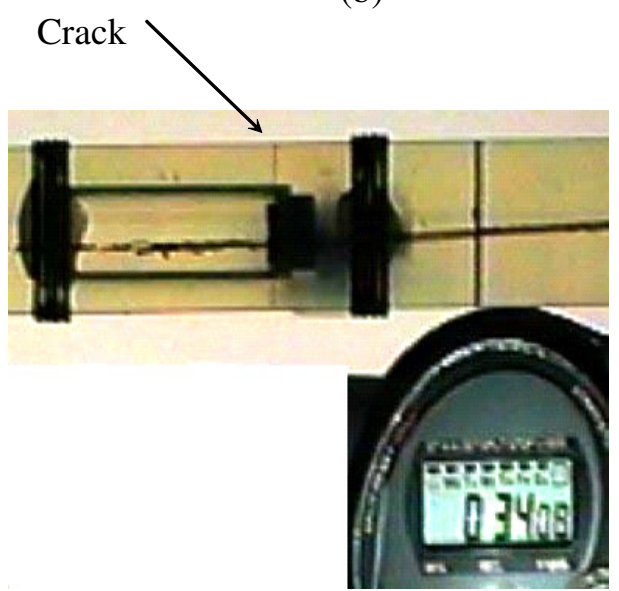

(d) (c)

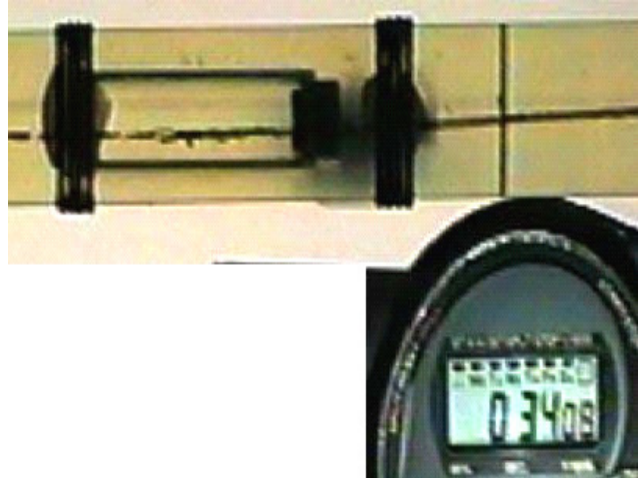

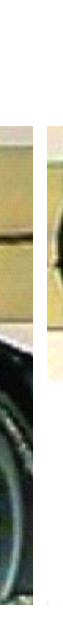


Figure 6

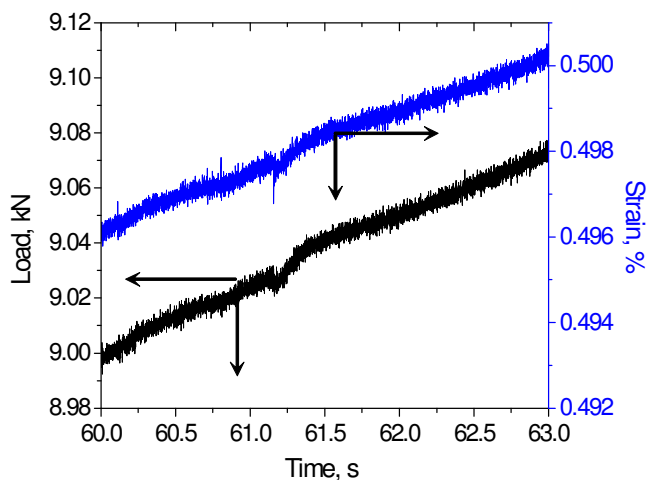

(a)

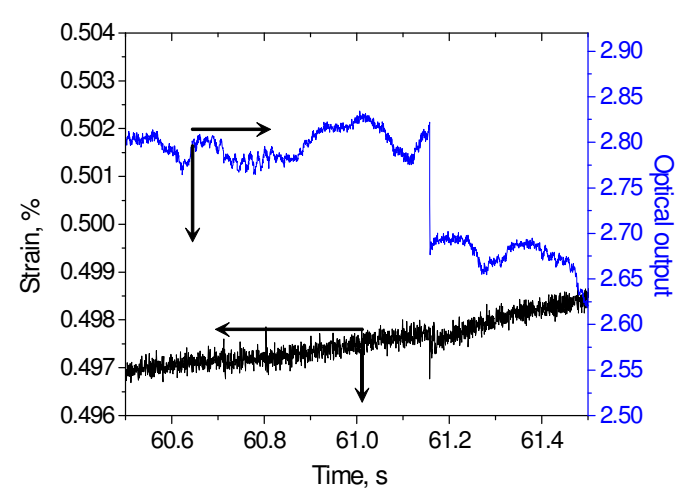

(b)

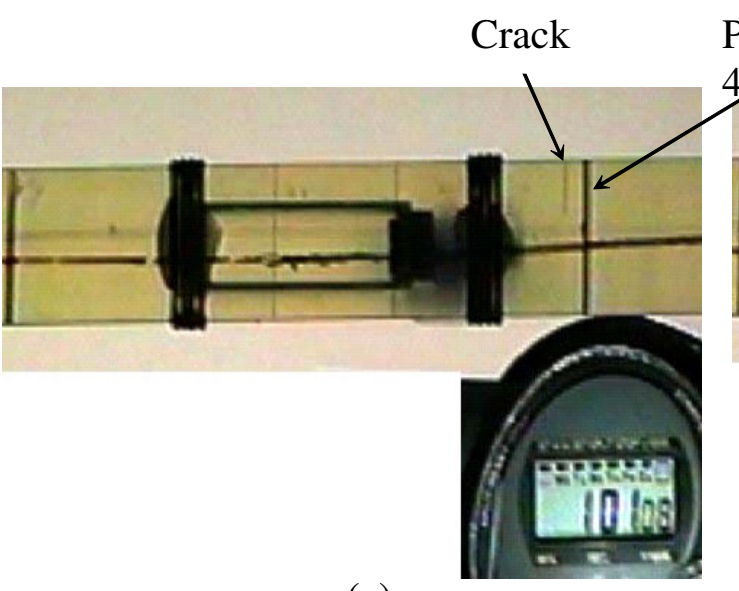

Position of the

Crack

$45^{\circ}$ splice

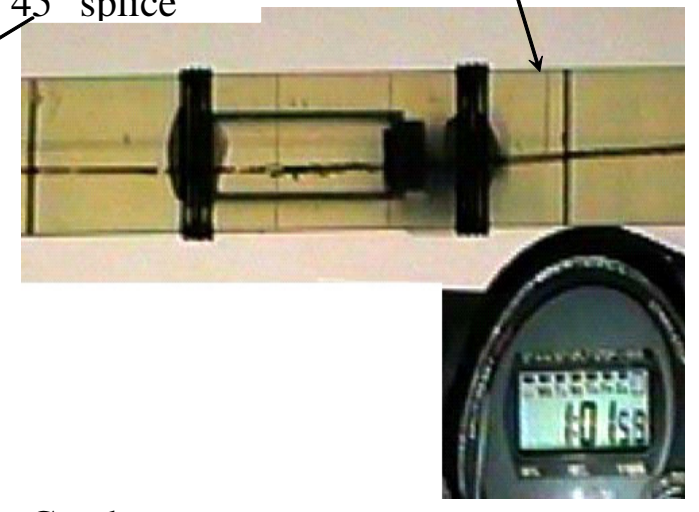

Crack

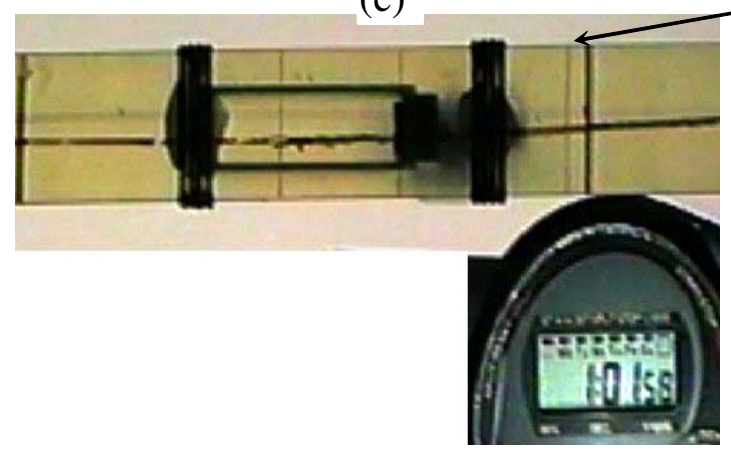

(d)

(e) 
Figure 7

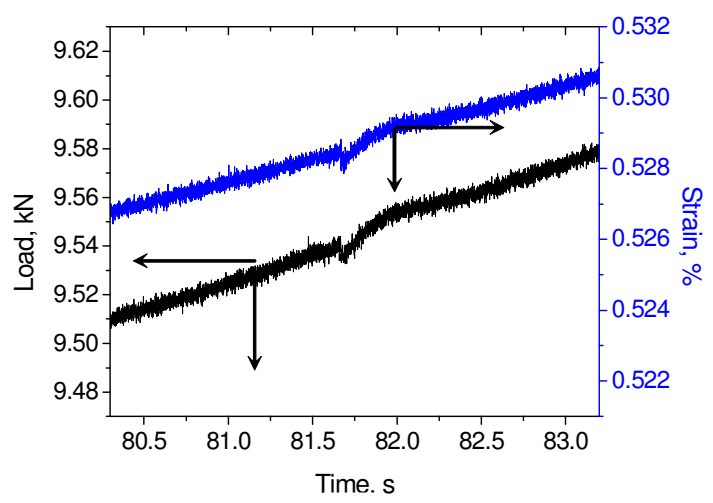

(a)

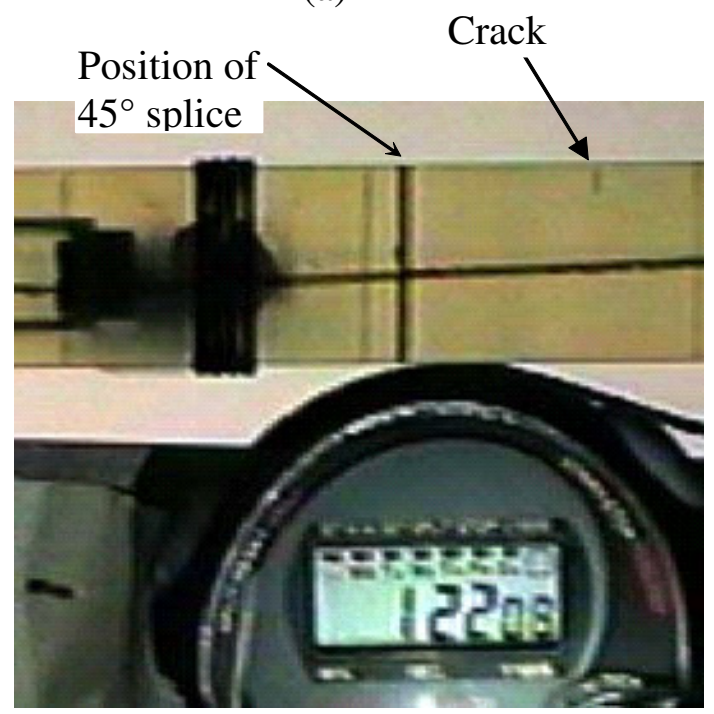

(c)

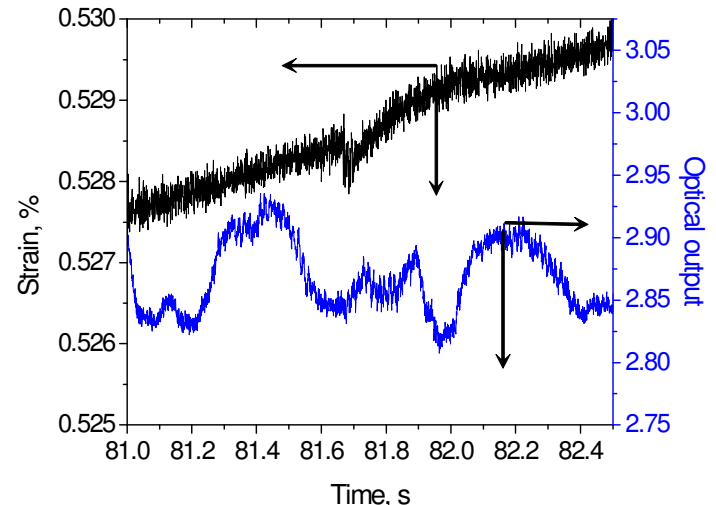

(b)

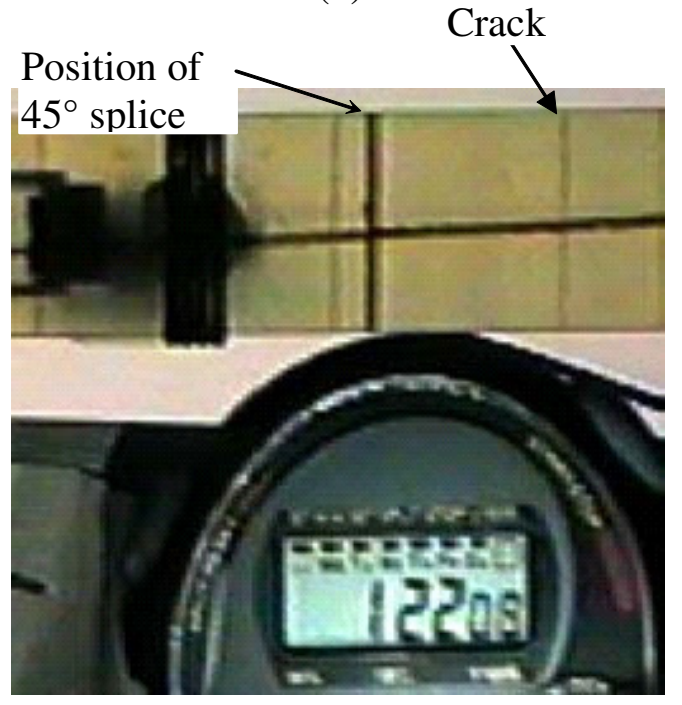

(d) 
Figure 8

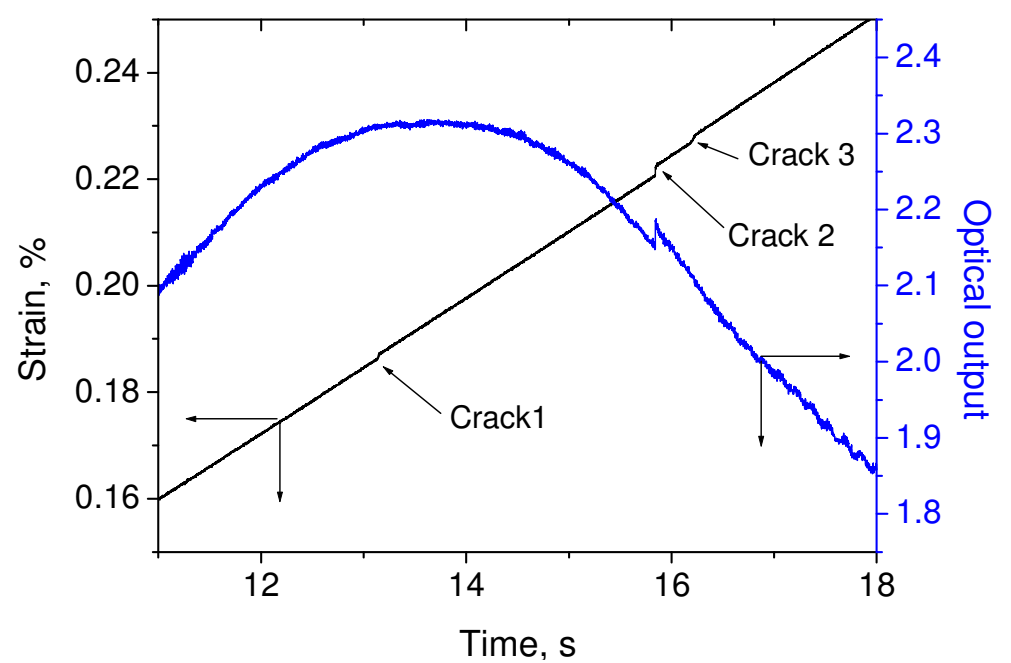

(a)

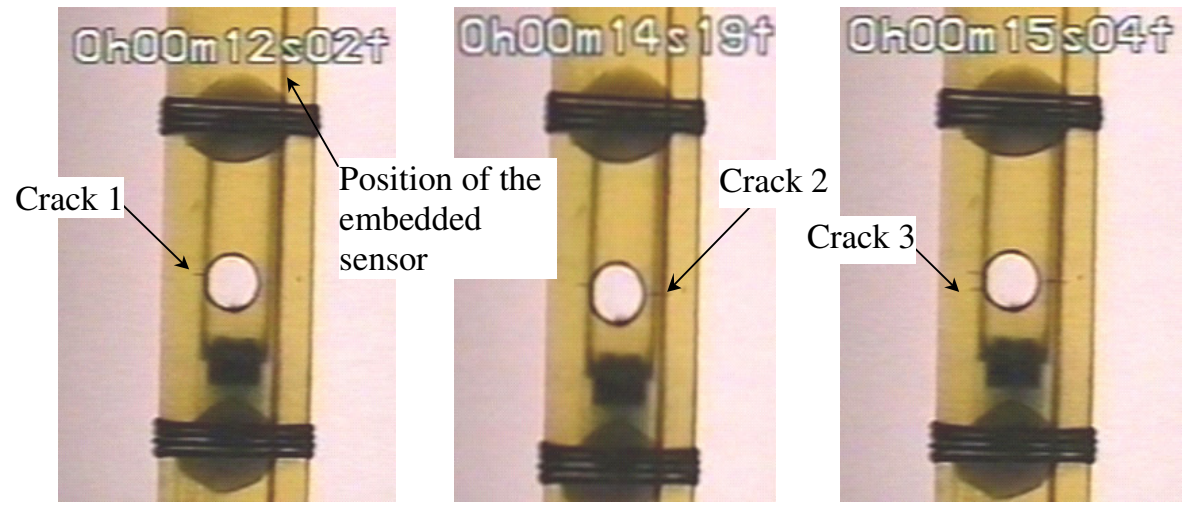

(b) 
Figure 9

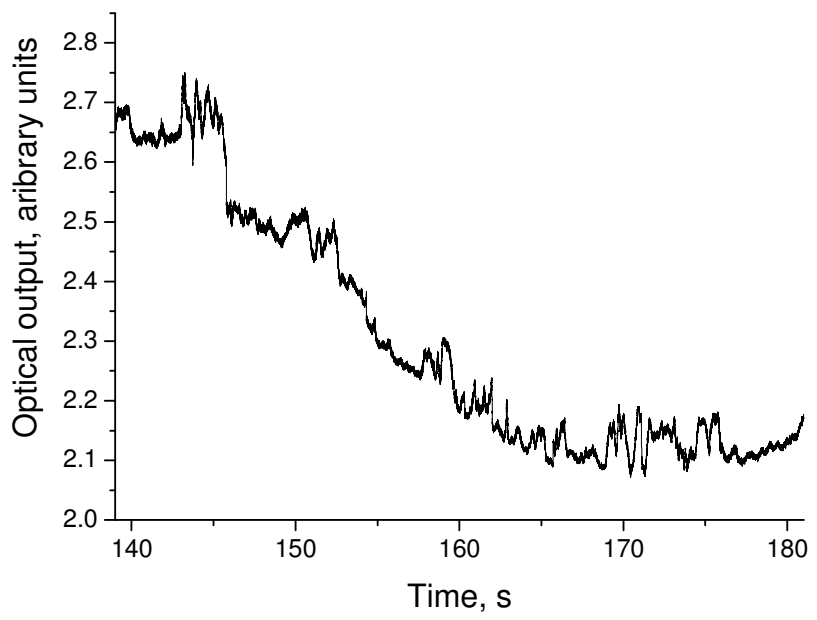


Figure 10

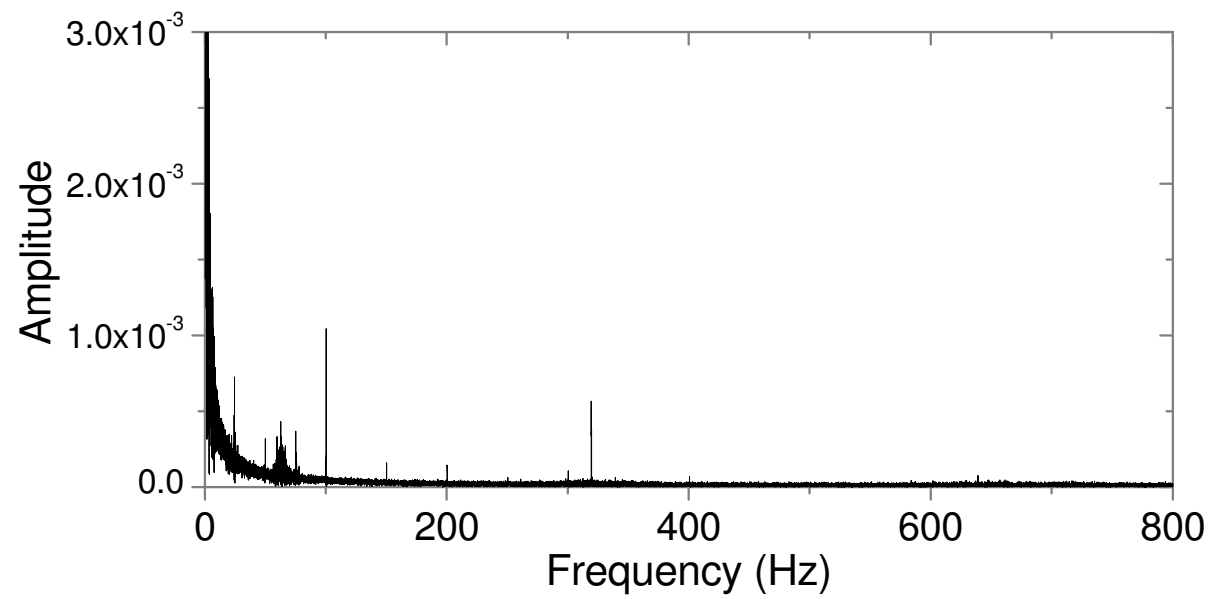

(a)

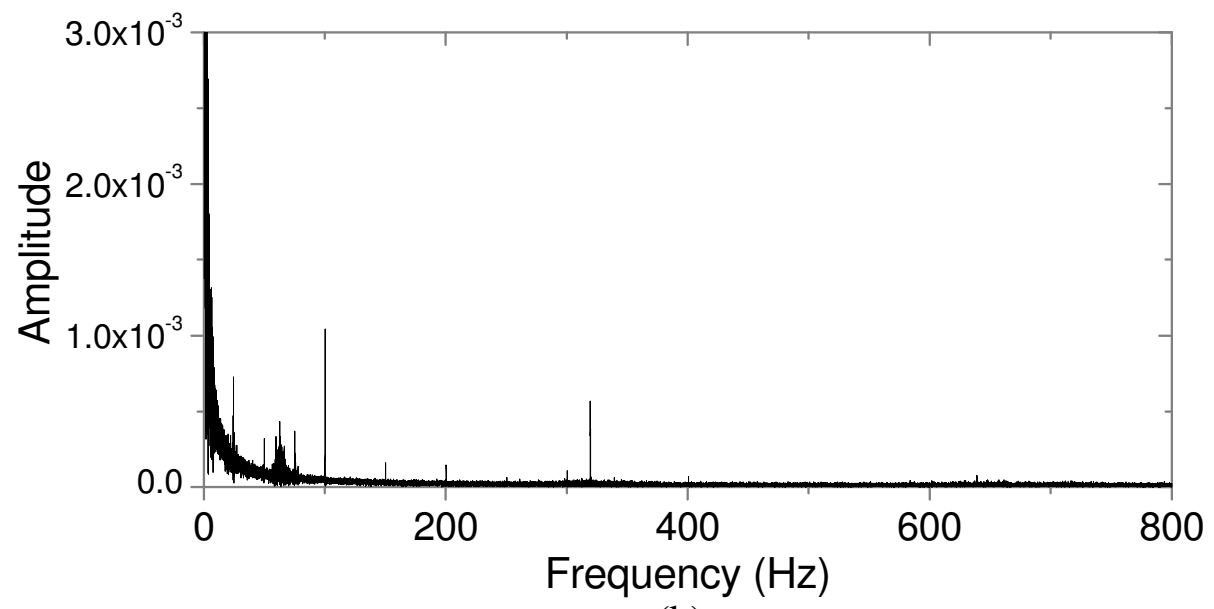

(b) 
Figure 11

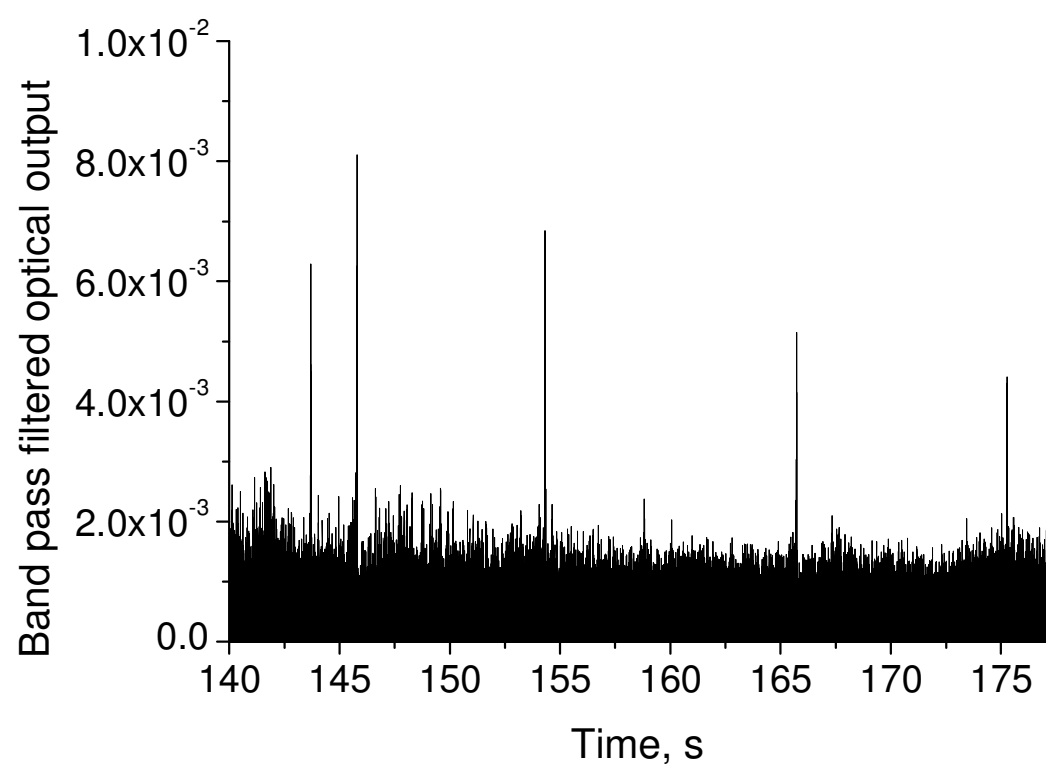


Figure 12

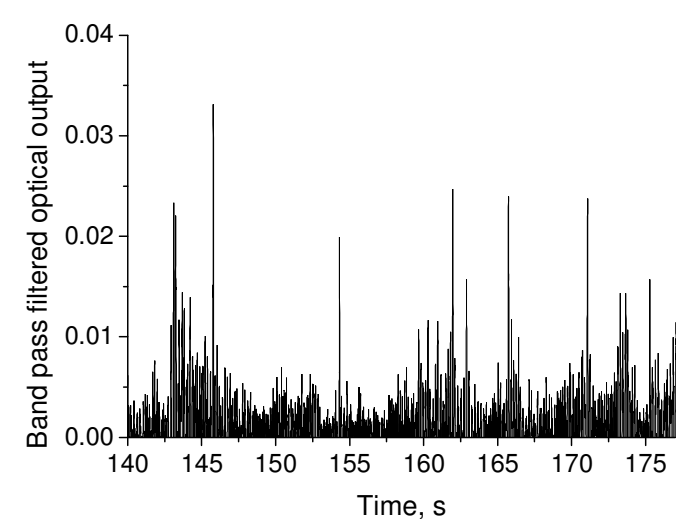

(a)

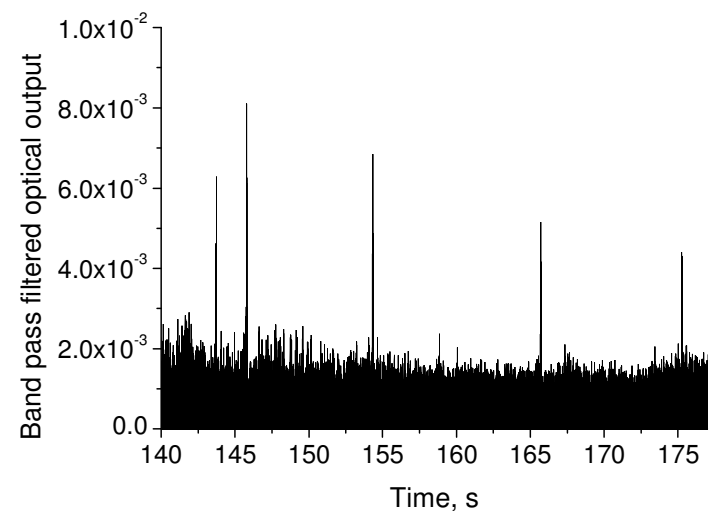

(c)

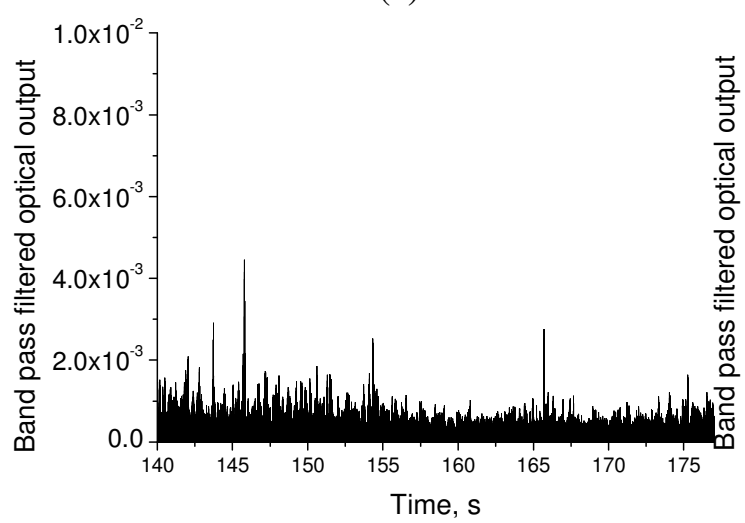

(e)

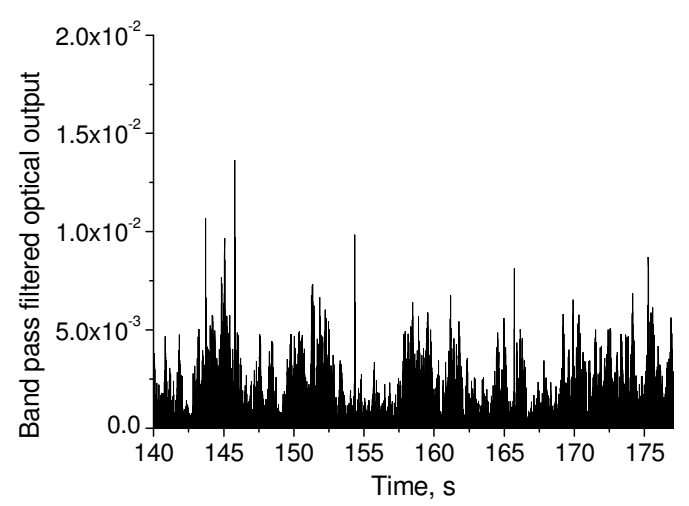

(b)

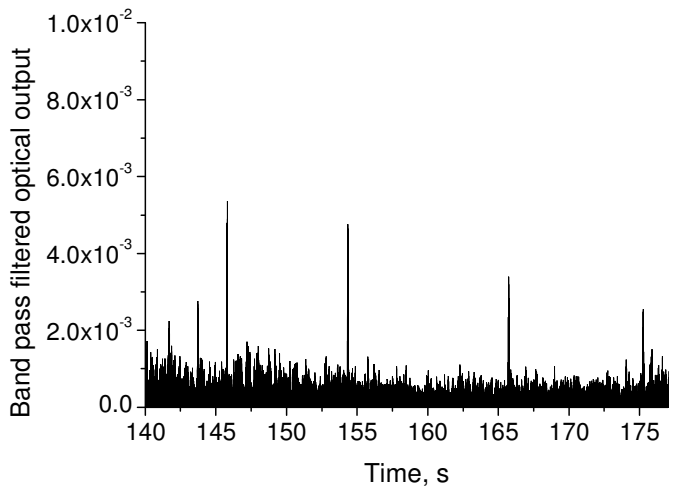

(d)

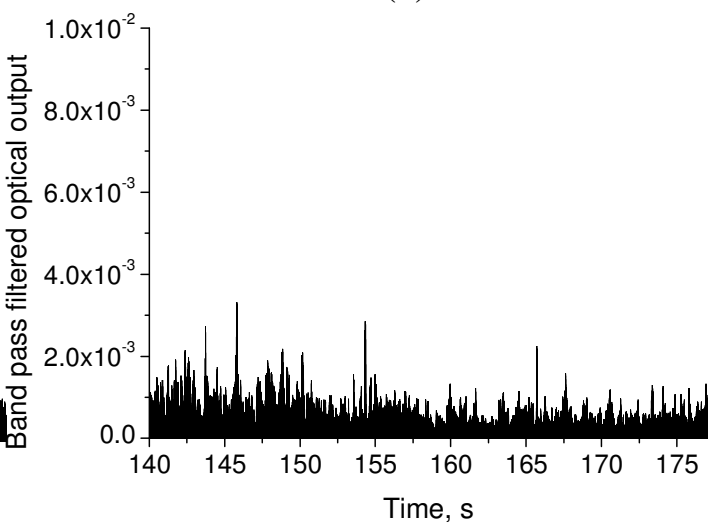

(f) 
Figure 13

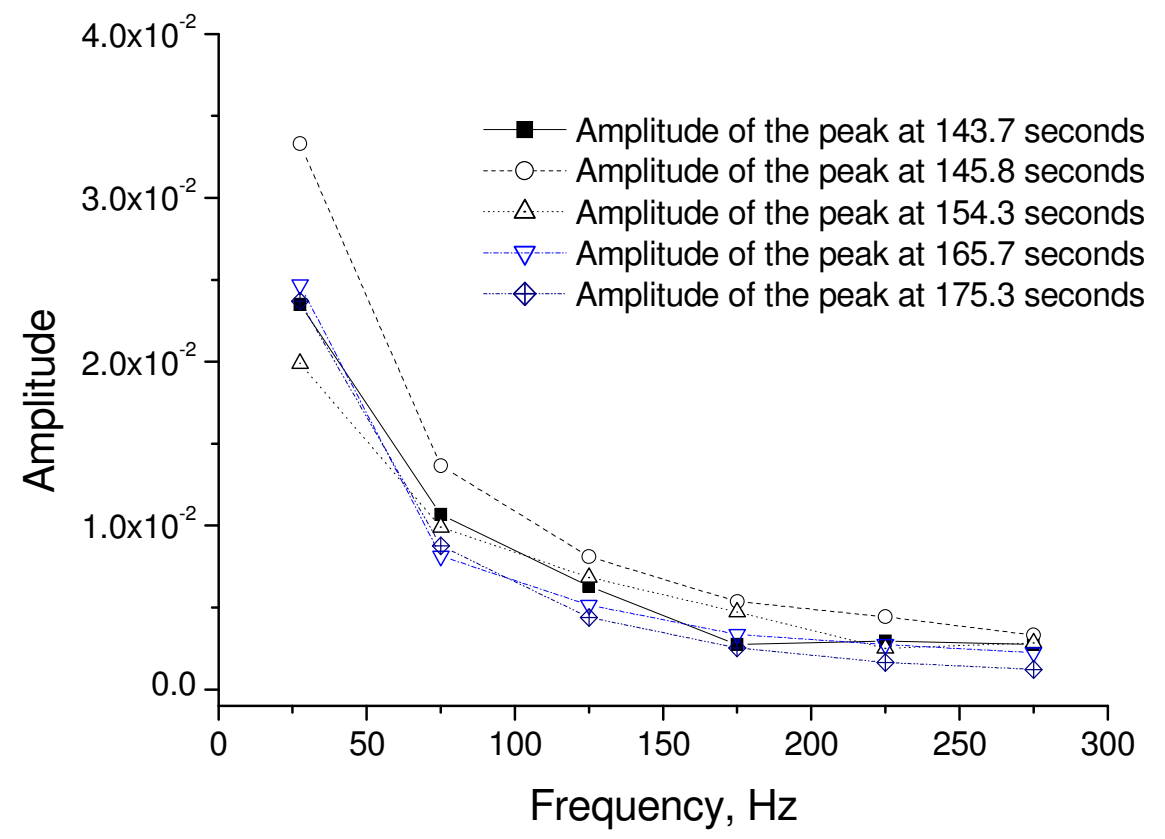




\section{Figure 14}
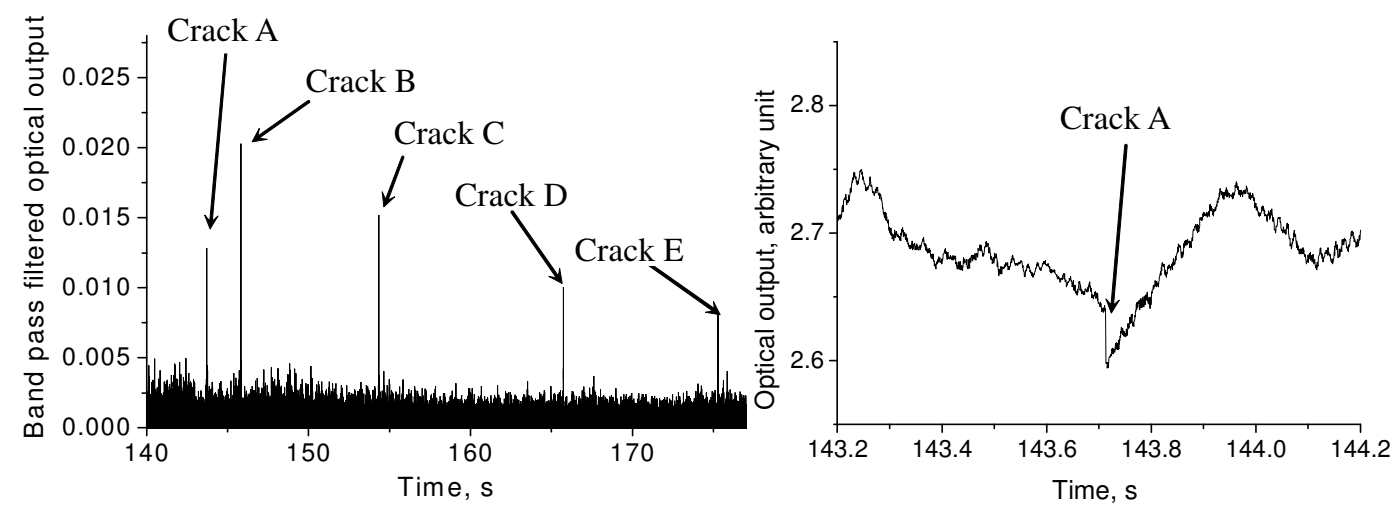

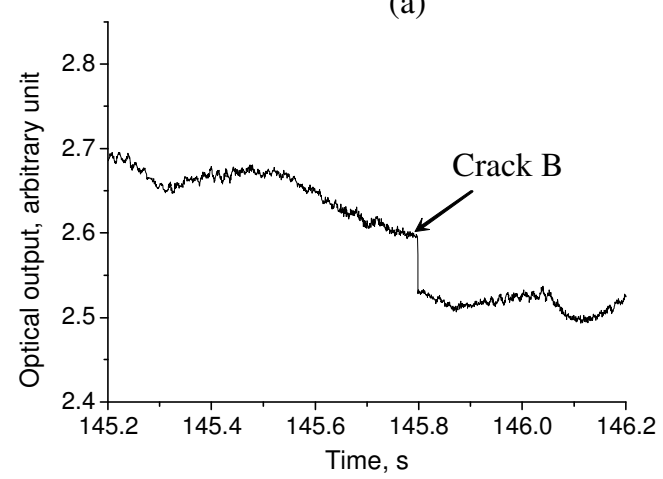

(c)

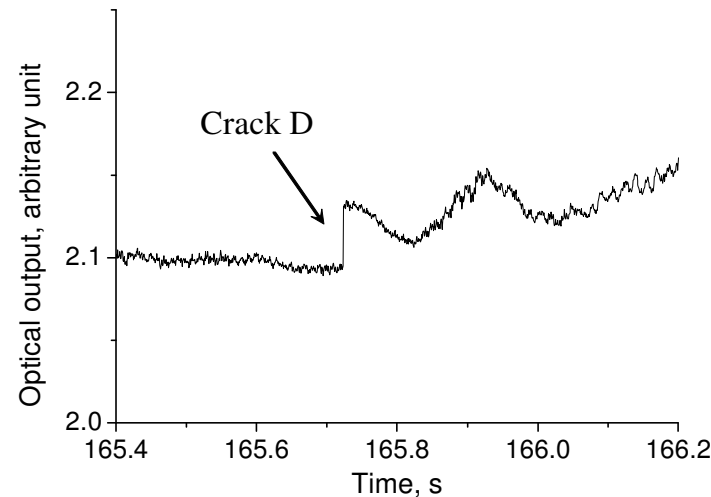

(e)

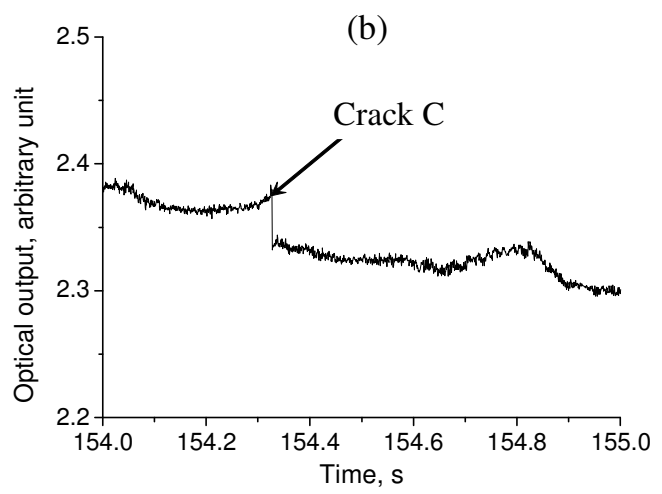

(d)

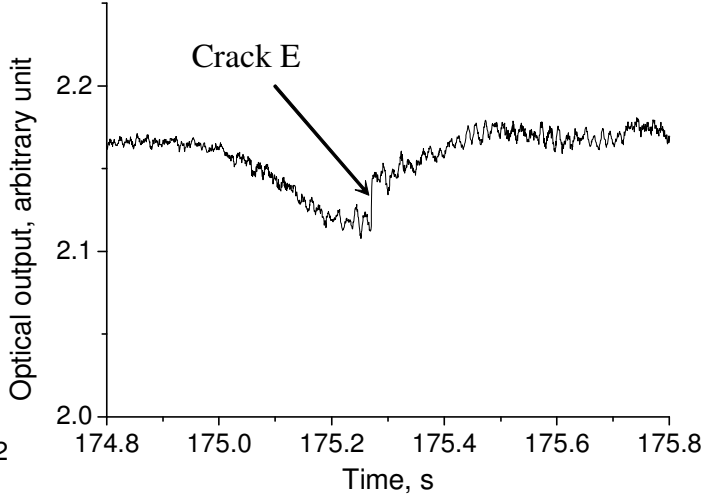

(f) 